Article

\title{
Rehabilitating Information
}

\section{Gary Fuhrman}

RR 1, 3241 Hwy 540, Little Current, ON, P0P 1K0, Canada; E-Mail: gnox@xplornet.com

Received: 21 December 2009; in revised form: 26 January 2010 / Accepted: 28 January 2010 /

Published: 3 February 2010

\begin{abstract}
In an early paper on logic, C.S. Peirce defined a concept of 'information' very different from the later conceptions which gave rise to 'information science', and indirectly to current problems such as an overload of 'useless information'. A study of further developments in Peircean semiotics, and in related conceptual frameworks including the cybernetics of Bateson and the cybersemiotics of Brier, reveals deep relations between Peirce's concept of information and the irreducibly triadic nature of signs. Since all sciences, indeed all cognition and communication, are semiotic processes, the core semiotic principle implicit in the Peircean concept may clarify how our uses of language and other symbolic media can actually inform-and thus transform-the way we humans inhabit the biosphere.
\end{abstract}

Keywords: cybersemiotics; pragmatism; Peirce; Bateson; information; meaning; logic; semiotics; dynamic systems; self-organization; autopoiesis; consciousness; cybernetics; ecology; Umwelt; Innenwelt

\section{Introduction}

Not long ago, news reports began to circulate about a mysterious 'colony collapse disorder' killing vast numbers of bees, especially in the United States. This was a major concern not only to beekeepers but to the whole food system, since the pollination services of bees are so important to agriculture. Attempts to locate the cause in some specific disease organism or any other single factor have borne little fruit. It now appears that the problem is systemic: commercial beekeeping practices, and indeed the whole agribusiness industry, have introduced stresses into the lives of bees which reduce their ability to cope with various pathogens and adverse conditions. This is typical of the problems now arising from human impact on the environment; and so is the solution proposed by beekeeper Philip Chandler [1]: 
"The remedy, as well as the blame, for the current parlous state of beekeeping lies with beekeepers themselves: nobody else knows enough or cares enough to take the necessary action. We need to share more information with each other and make more effort to educate the public, especially the next generation.”

The situation calls for two different kinds of information-sharing. One is between specialists (the beekeepers), and is therefore likely to employ a specialized idiom and terminology. Such a special idiom typically facilitates clear and unambiguous communication between members of the subculture it serves-but it also tends to make the knowledge encoded in it less accessible to those outside that subculture, i.e., 'the public'. Now, systemic problems cannot be solved unless the necessary information is available to the whole system which needs 'to take the necessary action' by transforming its own habits. Hence the need for the second kind of information-sharing, which would seem to require a 'language' (or conceptual structure) capable of informing the system as a whole of whatever crucial facts the specialists have found, without requiring the public to acquire a specialized idiom for the purpose.

However, this kind of problem represents only a tiny corner of the difficulties involved in deploying or even understanding information, just as the colony-collapse problem is only a small example (despite its importance) of the systemic problems confronting 21st-century society. What's needed, in my (non-specialist) view, is a new way of thinking, one broad enough to address the whole range of such problems, yet deep enough to provide real insight into them-theoretical insight with practical implications. Søren Brier's Cybersemiotics [2] offers a conceptual framework suitable for such a new way of thinking (and not incidentally, a critique of 'information science' as currently conceived). The aim of this paper is to provoke and promote the kind of semiotic thinking process which is absolutely necessary for making proper use of the cybersemiotic framework, or making any real sense of the current global situation. To this end, we will follow up on a train of thought launched by C.S. Peirce in 1867 [3], when he formally defined a concept of information which served him well through the rest of his career as a logician, especially in his pioneering work on semiotics.

Logically speaking, anything capable of informing must be some kind of sign, which implies its involvement in an irreducibly triadic relation. In the vernacular, though, we often speak of information as if it were a substance, measurable amounts of which can be stored, retrieved, transferred or copied from one place (or person) to another. This can be a useful metaphor, provided that we are aware of its limitations. Those limitations (and the usefulness of the metaphor) are most clearly revealed by considering information as a semiotic process. We sometimes do this implicitly, for instance when we speak of a person being 'well informed.' But in order to develop an explicit understanding of its role in semiotic processes or semiosis, we need to consider information in logical terms as the form of a genuine triadic relation.

To declare the triadic nature of semiosis, one need only define the 'sign' as something that represents something else (its 'object') to some third (interpreting) entity, so that the representation has some effect (its 'interpretant') on that third party. But such a declaration is not likely to have any significant effect on its interpreters-in other words, it will not really inform those on the receiving end of the message-unless they have already begun to think triadically. The problem is that it's too easy to interpret this (or any such) declaration according to mental habits which are less than fully triadic; and 
that, in a nutshell, is why this paper is so long and likely to try a reader's patience. It aims to lead the reader, by an unfamiliar path, into thinking triadically, rather than merely declaring the possibility of such thinking.

From a semiotic standpoint, the triadic nature of signs is rather like the buddha-nature from a Buddhist perspective: it is all-pervasive, and for that very reason difficult to recognize or notice-yet the recognition or realization of it can radically transform one's whole way of life. Since the inertia of habit is the great barrier to its transformation, a buddha will use whatever means are appropriate to break up that inertia; the analogous means adopted here, in a journal devoted to the subject of entropy, is to rethink the technical concept of information, since it is commonly correlated with the concept of entropy (for instance as 'negentropy'). This rethinking will focus on the alternative concept of Information defined, developed and deployed by Peirce as an essential component of his triadic semiotic logic. (I will henceforth capitalize the word Information when it refers specifically to this alternative concept.)

The other reason for this focus on Information, besides its conceptual connection with entropy, is that it affords an approach to genuine triadicity which will be unfamiliar in different ways to different groups of readers. First, those familiar with 'information science' and related disciplines will find here an alternate conceptual framework, closely allied to Brier's cybersemiotics. Second, even those familiar with Brier's major work on that subject may find something new in the close attention given here to Peirce's semiotically rigorous usage of the term 'information,' since Brier's book does not focus directly on this Peircean use of the word. Third, even those familiar with Peircean semiotics may not be aware of this concept of Information as a vital link between his early work on the logic of propositions and the more explicitly semiotic terminology he developed toward the end of his life. I believe that a detailed examination of this concept and its role in Peirce's work will show that he was fully aware of the triadicity of signs very early in his career as a logician, even though he did not begin to call his logic 'semiotic' until his final decade. And for those who are new to Peirce, this may serve to show that there are many terminological paths to the palace of genuine triadicity; coming at it from different angles may help to clarify its cogency and salience.

Finally, those accustomed to using the term 'information' in the common non-technical sense-and that includes all of us, regardless of membership in specialist communities-may find an unsuspected depth hidden behind the familiar word, if we have the patience to navigate the straits of Peirce's logical terminology, and the imagination to see how original his technical concept of Information was and is. (In many ways we have yet to catch up with Peirce even though he died almost a century ago.) In the second half of the essay i have tried to suggest how fruitful triadic thinking can be, both in theory and practice. Though this latter part goes well beyond anything Peirce said, and makes no attempt to match the rigor of his logic, it seems necessary to indicate (however vaguely) the practical implications of semiotic reasoning. Indeed, my secondary goal here is to show that Peirce's triadic logic is inseparable from his pragmatism (or pragmaticism, as he sometimes called it to distinguish it from other, more popular varieties of pragmatism).

The very end of Brier's Cybersemiotics [2] presents us with this stark choice:

"We begin manipulating the laws to our advantage through technology. If we do this well we will gain more semiotic freedom and a deeper understanding of ourselves and the 
universe. If not, we may well destroy both ourselves and most multicellular life systems on the planet."

Brier's subtitle warns us that 'information is not enough' to meet this kind of challenge or gain more semiotic freedom, but in this he is referring to the inherent limitations in the concept as developed by 20th-century 'information science.' If the developers of 'information theory' had fully recognized the triadicity of signs, they might not have imposed such limitations on the theory as they did, for they wouldn't have ignored (or taken for granted) the conditions that make a sign or message meaningful. In one of the few existing studies of 'Peirce's logic of information,' André De Tienne [4] writes:

"Peirce's suggestions may help clarify what is entailed in the concept of information at a time when contemporary information theorists of different stripes are facing problems stemming from having adopted incomplete or simplified definitions decades ago. It may well be that Peirce's semiotic logic provides a general theory capable of unifying all existing information theories, notably by showing exactly what function each fulfills within a common spectrum of concerns."

\section{Logic, Signs and Thirdness}

Peirce introduced his new definition of Information in the 1867 paper 'Upon Logical Extension and Comprehension' [3]. He used the newly defined term to clarify the two concepts named in the title, after reviewing the sometimes confused and divergent uses of those terms by earlier logicians. His original usage of the term continued, essentially unchanged, for over 40 years, as his logic developed into the fully semiotic form of his late writings.

As a concise introduction (in his own style) to Peirce's thought and the philosophical realism which is essential to it, consider the following account of his three phenomenological 'categories' (here called 'Universes of Experience'), from one of his last essays, published in 1908 [5] (p. 435):

"Of the three Universes of Experience familiar to us all, the first comprises all mere Ideas, those airy nothings to which the mind of poet, pure mathematician, or another might give local habitation and a name within that mind. Their very airy-nothingness, the fact that their Being consists in mere capability of getting thought, not in anybody's Actually thinking them, saves their Reality. The second Universe is that of the Brute Actuality of things and facts. I am confident that their Being consists in reactions against Brute forces, notwithstanding objections redoubtable until they are closely and fairly examined. The third Universe comprises everything whose Being consists in active power to establish connections between different objects, especially between objects in different Universes. Such is everything which is essentially a Sign,- - not the mere body of the Sign, which is not essentially such, but, so to speak, the Sign's Soul, which has its Being in its power of serving as intermediary between its Object and a Mind. Such, too, is a living consciousness, and such the life, the power of growth, of a plant. Such is a living institution,- - a daily newspaper, a great fortune, a social 'movement.'” 
Peirce here capitalizes words which he has defined within the paper in order to distinguish his usage from the vernacular-a practice also adopted in the present paper, beginning with the word 'Information.' The three 'Universes' identified here are typically called simply Firstness, Secondness and Thirdness in Peirce's work. We will consider them here in reverse order.

The Universe of Thirdness is inhabited by both Signs and living systems (including organic, psychical and social varieties). Writers in the emergent field of biosemiotics (such as Hoffmeyer [6]) have taken this a step further, regarding semiosis (the operation of signs) as definitive of life itself. Others, including the biomathematician Robert Rosen [7] and the sociologist Niklas Luhmann [8], have taken self-reference as essential to life. Semiosis and Peircean Thirdness do involve selfreference, but also other-reference, as both are involved in the functional triad of Sign, Object and Interpretant. All of this is involved in Peirce's concept of Information because Information is a property of signs (more specifically of symbols, but we will come to that later.)

At this point we need a definition of Sign, of which Peirce gave many; the one given here includes the concept of Form, and thus relates directly to Information. It is drawn from a letter to Victoria Welby, dated March 9, 1906 [9]:

"I use the word 'Sign' in the widest sense for any medium for the communication or extension of a Form (or feature). Being medium, it is determined by something, called its Object, and determines something, called its Interpretant or Interpretand. But some distinctions have to be borne in mind in order rightly to understand what is meant by the Object and by the Interpretant. In order that a Form may be extended or communicated, it is necessary that it should have been really embodied in a Subject independently of the communication; and it is necessary that there should be another subject in which the same form is embodied only in consequence of the communication. The Form, (and the Form is the Object of the Sign), as it really determines the former Subject, is quite independent of the sign; yet we may and indeed must say that the object of a sign can be nothing but what that sign represents it to be. Therefore, in order to reconcile these apparently conflicting Truths, it is indispensable to distinguish the immediate object from the dynamical object.”

The Immediate Object is 'the Object as cognized in the Sign and therefore an Idea' [5] (p. 495), while the Dynamical Object is 'the Reality which by some means contrives to determine the Sign to its Representation' [10] (4.536). This 'Reality' is typically factual, although the dynamical Object can be fictive if sufficiently actualized in the Sign to communicate its Form to a second Subject. But the dynamical Object is unequivocally other in relation to that second Subject, 'in which the same form is embodied only in consequence of the communication.' In the most familiar case (to us humans), this Subject can be the human interpreter of a linguistic (i.e., symbolic) sign-but the 'interpretive' process, even in that case, is not wholly under conscious control. Every sign determines an Interpretant which is another sign of the same dynamical Object. The immediate Object, on the other hand, is internal to the sign-process, and is therefore also internal to the mind (or 'quasi-mind') in which the cognition is taking place.

The next part of Peirce's letter [9] brings out the self-referential aspect of a 'dicisign,' and thus of a proposition, which is 'a Dicisign that is a Symbol' [10] (2.320): 
"The same form of distinction extends to the interpretant; but as applied to the interpretant, it is complicated by the circumstance that the sign not only determines the interpretant to represent (or to take the form of) the object, but also determines the interpretant to represent the sign. Indeed in what we may, from one point of view, regard as the principal kind of signs, there is one distinct part appropriated to representing the object, and another to representing how this very sign itself represents that object. The class of signs I refer to are the dicisigns. In 'John is in love with Helen' the object signified is the pair, John and Helen. But the 'is in love with' signifies the form this sign represents itself to represent John and Helen's Form to be. That this is so, is shown by the precise equivalence between any verb in the indicative and the same made the object of 'I tell you.' 'Jesus wept'='I tell you that Jesus wept."”

The same kind of analysis which distinguishes between two Objects leads us to distinguish three Interpretants [9]:

"There is the Intentional Interpretant, which is a determination of the mind of the utterer; the Effectual Interpretant, which is a determination of the mind of the interpreter; and the Communicational Interpretant, or say the Cominterpretant, which is a determination of that mind into which the mind of utterer and interpreter have to be fused in order that any communication should take place. This mind may be called the commens. It consists of all that is, and must be, well understood between utterer and interpreter, at the outset, in order that the sign in question should fulfill its function. This I proceed to explain.”

The names of the three Interpretants are not important for our purposes, but the concept of the commens or 'commind' is, because we need it to see how Information relates to communication. Continuing [9]:

"No object can be denoted unless it be put into relation to the object of the commens. A man, tramping along a weary and solitary road, meets an individual of strange mien, who says, 'There was a fire in Megara.' If this should happen in the Middle United States, there might very likely be some village in the neighborhood called Megara. Or it may refer to one of the ancient cities of Megara, or to some romance. And the time is wholly indefinite. In short, nothing at all is conveyed until the person addressed asks, 'Where?'- 'Oh about half a mile along there' pointing to whence he came. 'And when?' 'As I passed.' Now an item of information has been conveyed, because it has been stated relatively to a wellunderstood common experience. Thus the Form conveyed is always a determination of the dynamical object of the commind. By the way, the dynamical object does not mean something out of the mind. It means something forced upon the mind in perception, but including more than the perception reveals. It is an object of actual Experience.”

\section{Secondness and Externality}

This brings us to the second of Peirce's three 'Universes', for anything which is 'forced upon the mind in perception' or exists in the domain of 'actual Experience' belongs to the realm of Secondness. Secondness is the 'brute' force of actual or factual existence, experienced actively in will (exerting 
itself against resistance) and passively in perception (insofar as it is beyond any rational control). The dynamical object is not something clean out of the mind and wholly unrelated to it as a Kantian 'thingin-itself' is claimed to be; rather it is something in a 'real relation' to the mind, a relation occurring as a reaction or 'outward clash'. Of course, our concept of the relation, being a sign, belongs to the realm of Thirdness; but genuine Thirdness must include Secondness, not obliterate it. This does away with the old and misleading question of whether a perceived or conceived object is inside or outside of the mind; it must be both, if the object is real. Peirce had expressed this point as far back as 1871 [11] (p. 91):

"When a thing is in such relation to the individual mind that that mind cognizes it, it is in the mind; and its being so in the mind will not in the least diminish its external existence. For [the realist] does not think of the mind as a receptacle, which if a thing is in, it ceases to be out of. To make a distinction between the true conception of a thing and the thing itself is, he will say, only to regard one and the same thing from two different points of view; for the immediate object of thought in a true judgment is the reality."

Thus the dynamical and immediate objects of a true proposition are identical. We need to distinguish them because we can't be sure that any given proposition is true, but if we are realists, we engage in inquiry on the assumption that the truth about external reality can be known. 'The external,' according to Peirce, 'means simply that which is independent of what phenomenon is immediately present, that is of how we may think or feel; just as "the real" means that which is independent of how we may think or feel about it' [11] (p. 90). The very idea of external reality is thus grounded in the experience of Secondness, which is utterly familiar to all, since we cannot help sensing the difference between whatever we are currently conscious of and what clashes with it uncontrollably.

When Peirce says (above) that 'the Form conveyed' by a sign 'is always a determination of the dynamical object of the commind,' he appears to be reversing the usual direction of 'determination' whereby the Object determines the Sign, which determines the Interpretant to be 'thereby mediately determined by that Object' [5] (p. 478). But in symbolic communication at least, we can alternatively speak of the Sign 'determining' the Object in the sense of directing the interpreter's attention to it. In this case the 'fusion' of the two minds of Utterer and Interpreter has been achieved by directing their joint attention to the Form taken by their common experience of something existing independently of both minds. Generally speaking, 'determination' can be considered a kind of causality, so long as we do not limit our notion of that to the dyadic cause-and-effect mechanics which 'determine' what happens in physical systems. The determination embodied in semiosis is irreducibly triadic.

We could perhaps substitute 'system' for 'mind' in the above account without changing its essential meaning, since the Peircean philosophy does not split mind from body (or psychical from physical) as the Cartesian does. But notice that two levels of system are involved here: the individual level where utterer and interpreter differ in their experiences, and the level of 'commind' into which those two minds are 'fused' by virtue of sharing a 'well-understood common experience.' Information involves both levels, as well as a 'Form' which has been 'really embodied in a Subject independently of the communication' and in that sense is external to the process. It should also be clear that the 'fusion' of two minds into a commens does not obliterate all differences between them-if it did, no further Information could pass between them. One system can Inform another only when it is experientially 
Second to that other, which is why it takes a Third (the Sign) to connect them in the act of communication.

A conversation like the one described in Peirce's letter (above) is a prototypical example of communication, but semiosis is by no means limited to linguistic exchanges between humans. In an undated fragment [5] (p. 544), Peirce introduced the idea of a 'quasi-mind' in order to extend semiotics beyond the deliberate human use of signs:

"For the purposes of this inquiry a Sign may be defined as a Medium for the communication of a Form. It is not logically necessary that anything possessing consciousness, that is, feeling of the peculiar common quality of all our feeling, should be concerned. But it is necessary that there should be two, if not three, quasi-minds, meaning things capable of varied determination as to forms of the kind communicated.”

"As a medium, the Sign is essentially in a triadic relation, to its Object which determines it, and to its Interpretant which it determines. In relation to the Object, the sign is passive; that is to say, its correspondence to the Object is brought about by an effect upon the Sign, the Object remaining unaffected. On the other hand, in its relation to the Interpretant the Sign is active, determining the Interpretant without being itself thereby affected.”

"But at this point certain distinctions are called for. That which is communicated from the Object through the Sign to the Interpretant is a Form. It is not a singular thing; for if a singular thing were first in the Object and afterward in the Interpretant outside the Object, it must therefore cease to be in the Object. The Form that is communicated does not necessarily cease to be in one thing when it comes to be in a different thing, because its being is a being of the predicate. The Being of a Form consists in the truth of a conditional proposition. Under given circumstances, something would be true. The Form is in the Object, entitatively we may say, meaning that that conditional relation, or following of consequent upon reason, which constitutes the Form, is literally true of the Object. In the Sign the Form may or may not be embodied entitatively, but it must be embodied representatively, that is, in respect to the Form communicated, the sign produces upon the Interpretant an effect similar to that which the Object itself would under favorable circumstances.”

Anticipating the definition of 'genuine' at which we will shortly arrive, we can say that the effect of a genuine Sign on a system (such as a human individual or community) is to change its habits so that they are better oriented to the habits of the larger systems (communities or ecosystems) in which they are included. Peirce used the word 'habit' very broadly: having observed that 'the power of taking habits' is 'the most characteristic property of the nervous system' [11] (p. 264), he generalized it to the cosmological principle that 'all things have a tendency to take habits' [11] (p. 277). This is one expression of the 'law of mind' which, for Peirce (as for Gregory Bateson later), applies to the whole universe of life and not merely to humankind. Since we are human, however, we focus first on human thought-signs or concepts as the most familiar elements of 'mind' and then generalize from there. Applying (as Peirce often did) the Aristotelian distinction of form and matter, we could say that a 
concept is the form of a habit, its matter being the system's actual behavior as governed by that habit. This is one way of expressing Peirce's pragmatism, to which we will later return.

\section{Firstness and Form}

If Secondness is a 'real relation' and Thirdness a rational or mediating relation, Firstness is no relation at all. It is all-there-isness which is neither 'here' nor 'there'-a feeling, quality or idea in the absence of anything that could be other to it, including attention, intention or even existence. If you can imagine consciousness undivided into subject and object, then you can imagine a First which is not also Second to something else. Such a First is indescribable, but also indispensable to Pierce's semiotic analysis, and therefore to his concept of Information. The Form conveyed by a Sign could be considered the First in a triadic relation, as could the Sign also. In semiosis or perception, the Object as such can't be a First-as etymology indicates, it is 'thrown against' the Sign or the subject, and thus Second to it-but a quality predicated of the Object can be considered as a First, and this has semiotic implications.

By focusing on specific relations within the basic triad of Sign-Object-Interpretant, Peirce classified signs in various trichotomies. The most basic and important of these (for our purposes) designates types of signs by their relation to their objects:

(1) the icon, or sign of Firstness, is connected to its object only by resemblance to it in some respect.

(2) the index, of sign of Secondness, is actually connected to its object—usually either by 'efficient' causality, as when the impact of light makes its mark on a photograph, or by forcefully directing attention to the object, as a pointing 'index' finger may do if the object is a visible thing.

(3) the symbol, which 'is constituted a sign merely or mainly by the fact that it is used and understood as such, whether the habit is natural or conventional, and without regard to the motives which originally governed its selection' [12].

Human thoughts, concepts, words, propositions, arguments and texts are all symbols; indeed 'anthroposemiosis' (the human use of signs) is characterized by far greater use of symbols than any other semiotic domain of which we know. But there's a problem with symbols: the more habitual their usage, the more their real relation to their dynamic objects tends to be weakened or diluted. It is tempting to think of this as a psychological parallel to the second law of thermodynamics, whereby energy tends to be dissipated to the extent that it is harnessed by work. Energy cannot flow unless there is a difference or gradient between source and sink. This difference is a physical analogue of Peirce's Secondness, which (in the form of 'actual Experience') is crucial to the conveyance or 'flow' of information. This parallel, or something like it, has led some cyberneticians to think of information as analogous to energy, or as ‘negentropy'-a concept severely criticized by Brier [2] and others, along with the very idea of information as a substance which can 'flow'. This is itself an example of how a symbol can lose touch with its dynamical grounding in actual experience-one of two ways in which a symbol can become degenerate in a Peircean sense.

Peirce distinguished between genuine and degenerate symbols, borrowing these terms from the mathematical usage in which (for example) 'the degenerate form of an ellipse is a point, that of the parabola a straight line' [5] (p. 545) — that is, either of these is a degenerate form of conic section, since 'all the beautiful relations which characterize genuine conics have, in this form, quite petered out' [5] 
(p. 390). A genuine symbol is one which actively and experientially connects an idea (or First) with some thing, event or fact (or Second), so that its Interpretant inhabits a more well-informed system. In other words, it actively connects Objects in the two Universes of Firstness and Secondness. This it does by incorporating the functions of both icons and indices.

Taking semiotic logic back to its traditional roots, we could say that the prototypical case of a genuine symbol is a true proposition. We could also say that symbols are Informative precisely to the degree that they are genuine and not degenerate. To quote De Tienne [4] again,

"Of paramount importance to Peirce is that logic is concerned with truth, and that truth is not a disembodied property of arbitrary definitions, but a consequential measure of a proposition's capacity to represent 'real things', that is, things rooted in an actual world of action and reaction. Information is a concept that cannot be divorced from such a logical concern.”

The original 1867 paper [3] which introduced Peirce's new definition of 'information' began by examining the long-established logical concepts of 'extension and comprehension' and the various names applied to them over the centuries. Peirce declared his own preference for Hamilton's terms breadth and depth respectively. This pair was called denotation and connotation by Mill, but Peirce objected that the traditional usage of the latter term in logic was quite different. They have also been called extension and intension, but Peirce objected to the latter of this pair too, on the ground that it was too easily confused with intensity on the one hand and intention on the other.

Peirce later added supplementary notes to his paper in 1870 [3] and 1893 [10]. One of the latter includes this explanation [10] (2.407n):

"I restricted myself to terms, because at the time this chapter was first written (1867), I had not remarked that the whole doctrine of breadth and depth was equally applicable to propositions and to arguments. The breadth of a proposition is the aggregate of possible states of things in which it is true; the breadth of an argument is the aggregate of possible cases to which it applies. The depth of a proposition is the total of fact which it asserts of the state of things to which it is applied; the depth of an argument is the importance of the conclusions which it draws.”

Another 1893 note identifies Information as ‘the measure of predication’ [10] (2.418n), reinforcing its connection to propositional logic. Another ten years later, Peirce was thinking in more strictly semiotic terms, whereby the complementarity between breadth and depth appears as the complementarity between icon and index. It is by connecting the two triadically that the symbol is able to Inform. As De Tienne [4] explains:

"Peirce's elaborate discussion of dicisigns or propositions in the Syllabus of 1903 [5] (p. 275-85, 294-99) and in 'New Elements' [5] (p. 308-24) demonstrates clearly how such propositions always involve iconic and indexical elements-elements of depth and breadth—without which they could not inform. At the same time, however, neither icons nor indices have any informative power on their own. They are indispensable 'fragments of completer signs' [5] (p. 306), completer signs that are alone capable of adopting a communicable form.” 
In his original formulation, Peirce adopted the terms 'breadth' and 'depth' partly because 'they are very familiar. Thus, “wide” learning is, in ordinary parlance, learning of many things; “deep” learning, much knowledge of some things' [3] (p. 74). But in order to define them with the exactitude needed for technical terms, he had to introduce the concept of information [3] (p. 79):

"By the informed breadth of a term, I shall mean all the real things of which it is predicable, with logical truth on the whole in a supposed state of information...."

"By the informed depth of a term, I mean all the real characters (in contradistinction to mere names) which can be predicated of it (with logical truth, on the whole) in a supposed state of information, no character being counted twice over knowingly in the supposed state of information.”

'Real' things or characters, in Peirce's logic, are those which are what they are independently of anyone's belief about them. Peirce was a realist as opposed to an idealist in that he supposed that some of our ideas truly represent realities which do not depend on our minds for their being-although our cognition of them does depend on our minds, of course. He was also a realist as opposed to a nominalist, in that he took some of our general (or 'universal') concepts to be among those independent realities. This brand of realism certainly has metaphysical implications, but 'the metaphysical conceptions, as I need not waste words to show, are merely adapted from those of formal logic' [10] (1.625)—which for Peirce includes the deductive and inductive components of scientific method. Those who actually follow such a method must be virtual realists in this Peircean sense, regardless of what philosophical doctrine they profess; and this pragmatic realism is the key to what Peirce means by a 'state of information'.

In order to clarify this, we must first focus on logical breadth and depth, because Peirce defines information formally as the product of these two quantities. Notice the self-referential loop here, since (as we have seen) Peirce employed the term 'information' in his definitions of 'breadth' and 'depth'. Notice also that we are using the term 'quantity' here in its logical sense and not in the sense which applies to empirically measurable substances or countable collections. He gives the quantitative formula in geometrical terms, thus: 'Breath $\times$ Depth $=$ Area', defining Information as synonymous with Area [3] (p. 83).

\section{Breath $\times$ Depth $=$ Information}

Now let us consider how this applies to any proposition that you might utter or interpret. The subject of the proposition represents the object of your attention. (Note the difference between this usage of 'subject', as an essential part of a proposition, with the more Kantian usage we met above in Peirce's letter to Welby.) Insofar as the subject is a general term, it represents the set or class of entities among which you select the object of this particular Sign. ('Every sign has a single object, although this single object may be a single set or a single continuum of objects' [5] (p. 393).) The logical breadth of the proposition is a measure of how extensive the set of things denoted by the subject is, and thus it is also called logical extension.

Now, the object of any sign which can function as such for a human must be some portion of the totality which includes all possible objects of human attention. This totality we may call the human 
Umwelt, borrowing the term (as Brier [2] and many others do) from Jakob von Uexküll. The breadth of a sign then represents how much of this Umwelt is referred to or indicated by that sign. The actual referring or indicating is done by an index, which is the role of the subject in a proposition. 'Every subject partakes of the nature of an index, in that its function is the characteristic function of an index, that of forcing the attention upon its object' [13]. Speaking more strictly, however, a proper index must be nonverbal, as Peirce explains [10] (4.56):

"It seems certainly the truest statement for most languages to say that a symbol is a conventional sign which being attached to an object signifies that that object has certain characters. But a symbol, in itself, is a mere dream; it does not show what it is talking about. It needs to be connected with its object. For that purpose, an index is indispensable. No other kind of sign will answer the purpose. That a word cannot in strictness of speech be an index is evident from this, that a word is general - it occurs often, and every time it occurs, it is the same word, and if it has any meaning as a word, it has the same meaning every time it occurs; while an index is essentially an affair of here and now, its office being to bring the thought to a particular experience, or series of experiences connected by dynamical relations. A meaning is the associations of a word with images, its dream exciting power. An index has nothing to do with meanings; it has to bring the hearer to share the experience of the speaker by showing what he is talking about. The words this and that are indicative words. They apply to different things every time they occur. It is the connection of an indicative word to a symbolic word which makes an assertion.”

A relative pronoun or a proper name is about as close as a word can come to being a proper index; a linguistic symbol can do this job only to the extent that both the utterer and the interpreter share certain habits connecting the word with something existing in their common (physical or social) environment, and thus represented within their common conceptual system. Again following Uexküll, we can refer to that conceptual system or commonly internalized knowledge as the Innenwelt, 'a kind of cognitive map on the basis of which the organism orients itself to its surroundings' [14] (p. 6). The term 'cognitive' as used here does not denote a realm separate from the 'affective' realm of feeling and emotion, as it often does in 20th-century 'cognitive science.' We could also call this Innenwelt an internal 'model' as described in the biomathematical work of Rosen [7]. Considered as a sign, it is clearly a highly complex icon involving everything from bodily 'schemata' to the diagrams which (according to Peirce) are implicit in reasoning. (Peirce developed a system of 'Existential Graphs' as 'a System of diagrammatization by means of which any course of thought can be represented with exactitude' [10].) A functional cognitive map or 'model' is, like a Diagram, the 'form of a relation' [10] (4.530) between Umwelt and Innenwelt, i.e., between the external world with which the system or bodymind can interact and its own habits of interaction. These habits constitute the purposes or intentions embodied in that system as an autonomous agent.

We now have three sets of terms for explaining how a symbol can Inform, or change the 'state of information' within a system: it works by connecting depth and breadth, or icon and index, or Innenwelt and Umwelt. Applying this to a concept or thought-sign, its depth (intension, comprehension) amounts to its role within the conceptual system, while its breadth (extension or denotative power) is its relation to the real world external to that system-though not necessarily 
external to the sign-user as a psychobiological system, since her own body is part of that 'external world.' Again, the prototypical case of Information or 'conveyance of a Form' occurs in conversation between humans using language, but that's only because we are humans using language whenever we consider this situation. Genuinely informative semiosis can also occur through an internal dialogue. According to Peirce, 'all thinking is necessarily a sort of dialogue, an appeal from the momentary self to the better considered self of the immediate and of the general future' [9] (p. 195)—which he also called the 'deeper self' [10] (6.338). This suggests a growth in logical depth, a semiotic property which is possible for a person because 'the word or sign which a man uses is the man himself' [11] (p. 54).

The entanglement of humans with signs is further deepened by the circumstance that each individual user of a language must internalize it as a habit-system in order for the language-system to sustain a life of its own independent of any particular user. This may seem paradoxical, but it is only a special case of the principle that a 'law of nature' must actually Inform (determine the form of) natural events in order to qualify as a Law_or that a sign must have some breadth in order to mean anything. Each person internalizes or learns the language by coordinating its use with the Innenwelt-Umwelt relation - that is, with other habit-systems which guide the person's conduct. Once fully internalized, habits operate more or less automatically, so that conscious attention is free to focus on problematic or novel situations. New Information then leads to transformation of habits. Thus we have a spectrum of relative habituality, from totally spontaneous consciousness at one end, all the way to inert (totally habit-bound) matter at the other.

This vision of habituality as a broad spectrum sometimes leads to uncommon uses of common terms. For Peirce [5] (p. 455), a thought in the logical (not the psychological) sense can be embodied or expressed in physical facts and relationships even if that thought never crosses the consciousness of any thinker. If reasoning is a process of thought, then, it does not differ thereby from evolution, or from the actual operation of natural (e.g., thermodynamic) laws-insofar as these are continuing processes, and thus guide or inform possible future actions or events. Likewise by the pragmatic maxim, 'the entire meaning and significance of any conception lies in its conceivably practical bearings' [5] (p. 145)—not merely in how it has affected or does affect actual practice, or even in how it will affect practice in the future, but in how it would affect practice if and when the appropriate circumstances arose. The mutual relevance of those circumstances and the concept (or thought, or habit) virtually constitutes the depth of the symbol-just as 'the depth of a proposition is the total of fact which it asserts of the state of things to which it is applied' (quoted above).

Habits linking patterns of neural activity with responses (including consequent neural activity) are symbolic, incorporating both iconic and indexical signs into self-organizing systems guided by the mapping of internal models onto pragmatic situations into which behavioral patterns are interwoven. Since this mapping arises from and regulates intentionality, it is habitual and symbolic. Symbols 'represent their objects, independently alike of any resemblance or any real connection, because dispositions or factitious habits of their interpreters insure their being so understood' [5] (p. 460). 'Understanding' is here synonymous with 'interpretation' or generation of interpretants, which can range from instinctive actions to consciously articulated concepts. Even the latter, according to the pragmatic maxim, are meaningful only insofar as their objects have some conceivable effect on behavior. Though the indexical component of perception is necessary to the system's relations with the 
external world, the symbolic component is essential to the system's autonomy — that is, to its being a system in the first place.

\section{Habit, Meaning and Growth}

Every organism has its Innenwelt, but the human form of it differs greatly from other kinds in the preponderance of symbols among the signs habitually functioning within it. This in turn endows the human Umwelt with a plasticity quite unique among all animals of which we know. The typically human internalization of symbolic structures (what we call 'culture') is so unusual that we need a special name for the human Umwelt or objective world. Deely, borrowing from Husserl, calls it Lebenswelt [14] (p. 10). However, in order to emphasize that semiosis is by no means limited to humans, we can still express the nature of meaning in organic or systemic terms as a relationship between Umwelt and Innenwelt. Translating this back into logical terms, we could say that meaning is a relationship between breadth and depth, which is exactly how Peirce defined 'information'. As a logical (not physically measurable or countable) quantity and a semiotic property, Information is therefore inseparable from meaning. Both are inextricable from habit-systems.

To see how this development is grounded in the history of logic, consider this remark written by Peirce in 1902 [10] (8.119):

“As for the 'meaning,' logicians have recognized since Abélard's day and earlier that there is one thing which any sign, external or internal, stands for, and another thing which it signifies; its denoted breadth, its 'connoted' depth. They have further generally held, in regard to the most important signs, that the depth, or signification, is intrinsic, the breadth extrinsic.”

'Signification and application,' as defined by Peirce [15], is another pairing of logical terms corresponding to depth and breadth respectively. In that definition (and in several other works, including his original 1867 paper [3]), Peirce quoted the scholastic writer John of Salisbury in reference to 'what is well known to nearly everyone, namely that what common names (appelativa) mean and what they name are not identical. They name particular things, but their meaning is universal' (translation [3], p. 505). Nominantur singularia, sed universalia significantur: they name (or denote) singulars (individual things), while they signify universals (or generals); denotation considered as an abstract quantity is breadth, while signification is depth. 'A general term denotes whatever there may be which possesses the characters which it signifies,' says Peirce. These 'characters' belong to the Universe of Firstness and are most directly represented by iconic signs.

Information being logically the product of breadth and depth implies that a symbol, in order to be Informative, must incorporate both icons and indices into a 'completer' sign. If it does, it is a genuine symbol. If it doesn't, it fails to make a real connection between the Universes of Firstness and Secondness, or ideas and real things, and is therefore degenerate. A genuine symbol, on the other hand, being fully triadic, fully inhabits the Universe of Thirdness. Peirce's concept of information was developed to elucidate this triadicity of signs, as he explained in the 'Syllabus' prepared to accompany his Lowell Lectures of 1903 [10] (3.608): 
"the dyadic relations of logical breadth and depth, often called denotation and connotation, have played a great part in logical discussions, but these take their origin in the triadic relation between a sign, its object, and its interpretant sign; and furthermore, the distinction appears as a dichotomy owing to the limitation of the field of thought, which forgets that concepts grow, and that there is thus a third respect in which they may differ, depending on the state of knowledge, or amount of information."

In order to understand the growth which Peirce regarded as 'the law of mind' [11] (p. 354) and characteristic of semiosis, we need to see that genuine, triadic and informational are virtually synonymous terms applied to signs. We have seen that a genuine symbol must include both iconic and indexical elements; but we should also note that even a genuine index must incorporate an icon [5] (p. 171-2):

"It is desirable that you should understand the difference between the Genuine and the Degenerate Index. The Genuine Index represents the duality between the representamen and its object. As a whole it stands for the object; but a part or element of it represents [it] as being the Representamen, by being an icon or analogue of the object in some way; and by virtue of that duality, it conveys information about the object. The simplest example of a genuine index would be, say, a telescopic image of a double star. This is not an icon simply, because an icon is a representamen which represents its object by virtue of its similarity to it, as a drawing of a triangle represents a mathematical triangle. But the mere appearance of the telescopic image of a double star does not proclaim itself to be similar to the star itself. It is because we have set the circles of the equatorial so that the field must by physical compulsion contain the image of that star that it represents that star, and by that means we know that the image must be an icon of the star, and information is conveyed. Such is the genuine or informational index.”

"A Degenerate Index is a representamen which represents a single object because it is factually connected with it, but which conveys no information whatever. Such, for example, are the letters attached to a geometrical or other diagram. A proper name is substantially the same thing; for although in this case the connection of the sign with its object happens to be a purely mental association, yet that circumstance is of no importance in the functioning of the representamen.”

Of course 'genuine, degenerate' and 'informational' are relative terms; all signs are triadic in some sense or they couldn't be signs at all, yet in actual semiosis or communication, all symbols are degenerate to some degree. Whatever is genuinely Second to a system is external to it; 'degenerate seconds may be conveniently termed Internal, in contrast to External seconds, which are constituted by external fact, and are true actions of one thing upon another' [11] (p. 254). External seconds enter into 'real relations' as opposed to what the medieval logicians called 'relations of reason' [11] (p. 253). The Dynamical Object of a genuine sign, being 'an object of actual Experience' [9] (p. 197), is always outside of the interpreting system in the sense of being beyond its control—and therefore able to make a real difference to its self-control. 
Peirce explained in his 1867 paper that an increase in either breadth or depth, when not accompanied by a decrease in the other quantity, is an increase of Information. An increase of breadth results from learning of previously unknown or unrecognized things to which a concept applies, without any change in what the concept signifies. An increase of depth, on the other hand, is 'an increase of definiteness of the conceptions' applied to things already known [10] (2.422n). Peirce's original article went to some length to show that such increases of Information are possible, since this was not generally recognized. 'Many logicians say that the greater the extension of a term, the less its comprehension - that is, the more subjects it can be predicated of, the fewer the predicates that can be asserted of it universally. But this statement takes no account of increase of knowledge' [16]. In this statement, 'knowledge' is synonymous with Information. Increase of Information is the most welldefined form of the growth which, according to Peirce, is characteristic of signs.

Information tends to grow through the action of genuine Signs because their Interpretant signs are more fully developed than their predecessors in the semiotic sequence: each represents an increase of Information, which it can then pass on to its own Interpretant, theoretically ad infinitum. In practice, of course, it is quite possible for degeneracy to creep in: the iconic content of an index can drift away from the real qualities of its Dynamical Object, or the indexical content of a symbol can drift away from actual experience of the real thing. But the practice of scientific inquiry (including philosophy) is based on the instinctive hope or expectation that it leads to a higher state of Information, and the conscious self-control of human conduct is ultimately based on this same hope. Denial of that hope would mean denying that human knowledge of reality is possible-which no investigator really denies, for anyone who did would cease to investigate. Peirce's evolutionary philosophy and cosmology, and his pragmatism too, are based on this logical principle; here we will focus on the semiotic implications.

It might be asked how we can know that information is increasing through the action of signs; and indeed, 'information' conceived as something that can be stored and retrieved in measurable quantities must also be subject to decay, loss and destruction. But Peirce's concept of Information has nothing to do with storage or retrieval, and he does not argue that 'information' can be known to be increasing, as if it could be empirically measured or introspectively estimated. The expectation that information increases is rather 'what Kant calls a regulative principle, that is to say, an intellectual hope' [11] (p. 275). It is implied by the definition of a cognitive (semiotic) process as mediating between a mind and an independent reality which is nevertheless in real relation to it through the sign. This may clarify Peirce's 1908 proposition [5] (quoted above) that life, signs and 'the power of growth' co-inhabit the Universe of Thirdness, whether the growth is of a 'living consciousness' or of a plant.

\section{From Self-Organization to Communication}

Once his logical terminology is understood, Peirce's semiotic view of information correlates easily with more recent and now-familiar biophysical concepts of self-organization, autopoiesis, non-equilibrium thermodynamics, dissipative structures and complex adaptive systems. Organisms, persons and social institutions alike can now be regarded as living systems, which must be both open and closed. That is, they require autopoietic closure in order to maintain their identity as systems [17]; but they are also selectively open to flows of energy and information, else they would lack the 
resources for adapting to the environmental conditions from which they are partially insulated by their closure. They cope by developing habits which Inform their behavior. These 'habits', ranging all the way from physical structures to personal conduct to conceptual knowledge, must be maintained and modified within the system; yet they must be related to external events, by what Maturana and Varela called 'structural coupling' [17]. All of this applies to social as well as biological systems [8]. Any such complex adaptive system [18] must have some kind of boundary which determines what counts as internal or external with respect to that system. At the cellular level, this is definable in physical terms as the cell membrane. But how we define it at the higher systemic levels which carry on symbolic semiosis is a much more difficult question — and a significant one for the understanding of experience, meaning and information, all of which involve interaction (and thus difference) between the 'inner' and 'outer' worlds of the systems to which they pertain.

The most highly developed form of this interaction is the scientific quest for truth, which is a communal enterprise-and so is the deeper quest of religion, which in its pure form is an expression of a common human aspiration toward wholeness. For Peirce, reasoning and instinctive feeling or 'sentiment' are complementary aspects of evolution toward a higher unity [10] (1.673):

"the supreme commandment of the Buddhisto-christian religion is, to generalize, to complete the whole system even until continuity results and the distinct individuals weld together. Thus it is, that while reasoning and the science of reasoning strenuously proclaim the subordination of reasoning to sentiment, the very supreme commandment of sentiment is that man should generalize, or what the logic of relatives shows to be the same thing, should become welded into the universal continuum, which is what true reasoning consists in. But this does not reinstate reasoning, for this generalization should come about, not merely in man's cognitions, which are but the superficial film of his being, but objectively in the deepest emotional springs of his life. In fulfilling this command, man prepares himself for transmutation into a new form of life, the joyful Nirvana in which the discontinuities of his will shall have all but disappeared.”

As a way of sensing our collective growth toward completeness, we may imagine 'the joyful Nirvana' as a future state, although we may doubt that any individual or collective self will ever be aware of that state (if such awareness is even conceivable). This 'Nirvana,' and likewise the 'Truth' at which science and philosophy aim, are ideal limits in the mathematical sense. However, they differ from mathematical objects in that we can only see them from inside the process which generates them; we can't observe them from outside. We have no means of constructing or conceiving a diagram that includes the Absolute Truth, or a state of Universal Continuity; nor could we represent our present state of information as a point (or set of points) on such a diagram in order to measure the distance between that point and the limit we approach. That distance is, we may say, the engine of semiosis, creating the space in which it can happen-a space too vast to measure: 'though in no possible state of knowledge can any number be great enough to express the relation between the amount of what rests unknown to the amount of the known, yet it is unphilosophical to suppose that, with regard to any given question (which has any clear meaning), investigation would not bring forth a solution of it, if it were carried far enough' [11] (p. 139-40). Indeed that is what 'every man of us virtually assumes' [10] (5.430). 
Although we can't see the whole of semiosis, we can fully engage in it because our own growth is wholly entangled with the growth of Information [11] (p. 54):

"Man makes the word, and the word means nothing which the man has not made it mean, and that only to some man. But since man can think only by means of words or other external symbols, these might turn round and say: 'You mean nothing which we have not taught you, and then only so far as you address some word as the interpretant of your thought.' In fact, therefore, men and words reciprocally educate each other; each increase of a man's information involves, and is involved by, a corresponding increase of a word's information.”

This ‘increase of information’ proceeds toward ‘the ideal state of complete information' [11] (p. 54)'ideal' meaning 'the limit which the possible cannot attain' [11] (p. 52). In this respect, the life of a general idea (or sign) and the life of a person (individual or corporate) are analogous to one another. Peirce returned to this idea in his 1892 paper on 'Man's Glassy Essence' [11] (p. 350):

"The consciousness of a general idea has a certain 'unity of the ego' in it, which is identical when it passes from one mind to another. It is, therefore, quite analogous to a person; and, indeed, a person is only a particular kind of general idea.... every general idea has the unified living feeling of a person.”

'All that is necessary' (wrote Peirce in the next paragraph) 'to the existence of a person is that the feelings out of which he is constructed should be in close enough connection to influence one another.' This, he argued, applies as well to communities as to individual persons. 'Esprit de corps, national sentiment, sym-pathy, are no mere metaphors. None of us can fully realize what the minds of corporations are, any more than one of my brain cells can know what the whole brain is thinking. But the law of mind clearly points to the existence of such personalities' [11] (p. 350).

Although 'such personalities' may (or must) exist, and may influence individual persons, the difference in scale would seem to eliminate any common ground of experience between human and ‘corporate' embodiments. Symbolic systems such as human languages do not bridge this gap, because no symbolic utterance can be understood unless its interpreter has prior or 'collateral' experience of its object-experience which cannot be conveyed by word or diagram [10] (3.419). This prior experience which allows a sign-reader to re-cognize the object of a symbol must be embodied in the individual organism, hence private in that sense. Yet language itself is a social phenomenon, and any meaning, truth or information conveyed by means of it must be transpersonal. Indeed, the very concept of an individual as a person can be meaningful only in the context of a community or social system. The 'circle of society (however widely or narrowly this phrase may be understood), is a sort of loosely compacted person, in some respects of higher rank than the person of an individual organism' [5] (p. 338). To put it more bluntly, 'what are we? Mere cells of the social organism' [10] (1.673).

In the current context, though, some new questions arise from this answer to the question of what we are. How 'loosely compacted' can a system be, and still be considered a 'person'? In what respects is a society 'of higher rank' than the individual? Granted that human values arise in a social context, we must also recognize that they arise from human experience, and learning from that experiencelearning which occurs at the scale of the individual human body. What happens when a legally 
constituted 'person' such as a corporation cuts itself off from the experience of human-scale organisms affected by its actions, and makes its decisions on the basis of an abstract 'bottom line' such as profitability? More generally, how does the scale of 'personhood' affect what counts as Information for that person? It seems obvious enough that Information is crucial in any process of self-organization or self-control. But it is not so clear whether such processes actually work at a higher-than-human scale, or if they do, how they can be informed by human-scale experience. If they can't, then a global process such as economic 'growth' would appear to be a degenerate form of true semiotic growth. In the rest of this paper we will consider some answers to these questions, to which Peirce's concept of Information would suggest answers quite different from those implied by some other concepts of information.

\section{From Information to Anticipation}

We can only imagine what life is like for a 'corporation' or larger-scale organism, or what its intentions are. But perhaps we can better appreciate the human community as the context of all communication among ourselves if we think of it as an ideal unity-a single Human Body, including all humans as members-toward which we grow through semiosis. This certainly speaks to the quasi-religious sense of belonging to something bigger and more significant than a single human life can encompass; and this necessarily vague feeling pervades Peirce's references to 'Reality' and 'Truth.' In 1868, Peirce had already linked the concepts of community and reality in a paper which traced a typical cognitive or semiotic process back to its ideal (nonexistent) origin as well as projecting it forward to an ideal (nonexistent) limit called the Truth. This remarkable passage [11] (p. 52) illuminates the connection between Peirce's realism and the logical concept of an 'increase of knowledge'. He begins by describing how an increase of Information appears to us (even though we cannot step outside of semiosis to measure it):

"At any moment we are in possession of certain information, that is, of cognitions which have been logically derived by induction and hypothesis from previous cognitions which are less general, less distinct, and of which we have a less lively consciousness. These in their turn have been derived from others still less general, less distinct, and less vivid; and so on back to the ideal first, which is quite singular, and quite out of consciousness. This ideal first is the particular thing-in-itself. It does not exist as such. That is, there is no thing which is in-itself in the sense of not being relative to the mind, though things which are relative to the mind doubtless are, apart from that relation. The cognitions which thus reach us by this infinite series of inductions and hypotheses (which though infinite a parte ante logice, is yet as one continuous process not without a beginning in time) are of two kinds, the true and the untrue, or cognitions whose objects are real and those whose objects are unreal. And what do we mean by the real? It is a conception which we must first have had when we discovered that there was an unreal, an illusion; that is, when we first corrected ourselves. Now the distinction for which alone this fact logically called, was between an ens relative to private inward determinations, to the negations belonging to idiosyncrasy, and an ens such as would stand in the long run. The real, then, is that which, sooner or later, information and reasoning would finally result in, and which is therefore independent 
of the vagaries of me and you. Thus, the very origin of the conception of reality shows that this conception essentially involves the notion of a COMMUNITY, without definite limits, and capable of an indefinite increase of knowledge. And so those two series of cognitions - the real and the unreal—consist of those which, at a time sufficiently future, the community will always continue to reaffirm; and of those which, under the same conditions, will ever after be denied. Now, a proposition whose falsity can never be discovered, and the error of which therefore is absolutely incognizable, contains, upon our principle, absolutely no error. Consequently, that which is thought in these cognitions is the real, as it really is. There is nothing, then, to prevent our knowing outward things as they really are, and it is most likely that we do thus know them in numberless cases, although we can never be absolutely certain of doing so in any special case.”

Having defined truth in terms of 'the long run,' Peirce here explains why this does not imply that we can't know anything now. He also anticipates Wittgenstein's observation [19] that there is no private language. In semiotic terms, the whole triad of Sign, Object and Interpretant must be in the public domain, even when a person is 'talking to himself,' if his talk signifies anything. In this light, let us turn to the role of the Interpretant in the concept of Information.

As defined by Peirce, the Interpretant is another sign determined by a Sign to represent the same Object that the first Sign represents. But in order to be a Sign in its turn—in order to mean anything-it must determine another Interpretant, 'and so on ad infinitum,' as Peirce often said. This process can have no end within semiosis, but it can (indeed must) have a limit, just as the process of inquiry does. Peirce wrote in 1904 [5] (p. 304) that 'the "Truth", the fact that is not abstracted but complete, is the ultimate interpretant of every sign'-which it approaches 'by being joined with other signs,' just as humanity 'should become welded into the universal continuum.' But this ultimate logical interpretant (as he called it c.1906), being the very limit of semiosis, is not itself a sign. What is it then? 'It can be proved that the only mental effect that can be so produced and that is not a sign but is of a general application is a habit-change; meaning by a habit-change a modification of a person's tendencies toward action, resulting from previous experiences or from previous exertions of his will or acts, or from a complexus of both kinds of cause' [10] (5.476).

This is where Peirce's realism intersects with his pragmatism, which (crudely expressed) is the doctrine that the real meaning of any concept consists of its conceivable implications for future conduct. Since any system's habits are the essential guides its conduct, real increases or growth of Information must have some effect on the habits which define the system's relations to the more inclusive systems which constitute its context. In other words, Information is a systemic relation between external reality and internal habits, and any increase of Information is a step toward completeness of that coupling-which must be a living relation, an ongoing process. We can still speak of 'information' as something that can be stored, retrieved or transmitted (as information science often does), just as we can speak of something as a 'sign' when it is not actually functioning as such. But it can be counted (or measured) as Information, or knowledge, only to the extent that it can make a real difference in the way we conduct ourselves as systems embedded in systems. 
As Peirce wrote [10] (5.542):

"Knowledge which should have no possible bearing upon any future experience - bring no expectation whatever - would be information concerning a dream. But in truth no such thing can be presumed of any knowledge. We expect that in time it will produce, or reinforce, or weaken some definite expectation.”

This emphasis on expectation, which is central to Peirce's pragmatism, has its biological parallel in Robert Rosen's work on anticipatory systems (e.g., [20]). Rosen defined living or complex systems as those which develop internal models of themselves and their environments to guide the system's relations with the external world. This 'model'-essentially what we have called the Innenweltprovides the system with expectations of what will happen, which are in turn modified (Informed) by differences between what is expected and what actually happens. This cybernetic feedback loop is formalized in the scientific method: a hypothesis is tested by predicting what would occur in specified circumstances if it were true, and then observing what actually happens in those experimental circumstances. If the predicted event does not occur, or something positively surprising happens, the hypothesis is falsified (or modified). But the usual reason for generating a hypothesis in the first place is that something happens which violates a habitual expectation and thus calls it into question. Driving this whole process, as we have seen above, is the 'hope' of arriving at a true expectation, one which won't be violated in the future. All of this arises from the interplay of breadth and depth which is rooted in the nature of semiosis itself. "Because every sign "stands to" or addresses itself to an interpretant, every sign—at least, every symbolic sign—is anticipating another sign’ [4].

\section{Abstraction, Inhibition and Self-Control}

Humans, as the 'symbolic species' [21], have evidently taken anticipation further than other animals; the physiological basis of this seems to be our highly developed frontal lobes. According to Walter Freeman [22],

"The frontal lobe refines and elaborates the predictions of future states and possible outcomes toward which intentional action is directed.... Two aspects are noteworthy. The dorsal and lateral areas of the frontal lobe are concerned with cognitive functions such as logic and reasoning in prediction. The medial and ventral areas are concerned with social skills and the capacity for deep interpersonal relationships.”

The close proximity of these functions in the brain suggests a physiological explanation of why 'logic is rooted in the social principle,' as Peirce put it [11] (p. 149). Among the logical functions which are closely entwined with the social phenomenon of language, one of the key instruments of high-level anticipation is the process of abstraction.

In order to conceive of a concept's implications for future conduct-that is, of its meaning-we have to objectify its depth. 'When we speak of the depth, or signification, of a sign we are resorting to hypostatic abstraction, that process whereby we regard a thought as a thing, make an interpretant sign the object of a sign' [5] (p. 394). 'That wonderful operation of hypostatic abstraction by which we seem to create entia rationis that are, nevertheless, sometimes real, furnishes us the means of turning predicates from being signs that we think or think through, into being subjects thought of' [10] 
(4.549). The question of whether apparently mind-created things can be real was the crux of debate between the scholastic realists and the nominalists, and Peirce declared himself (here as elsewhere) on the realist side by saying that entia rationis are 'sometimes real.' But why bother to think about thought-signs at all? Because our quintessentially human faculty of self-control depends on our doing so. Abstraction is 'the basis of voluntary inhibition, which is the chief characteristic of mankind' [5] (p. 394); and 'self-control of any kind is purely inhibitory' [5] (p. 233).

If it seems a bit strange to say that voluntary inhibition (rather than voluntary action) is 'the chief characteristic of mankind,' reflect that in practice we cannot choose to do anything unless we can imagine a range of possible actions, or at least some ideal of practice which can be compared to the action contemplated. The person who reacts automatically to any situation, without stopping to think whether another response might be better, is incapable not only of self-control but of any deliberate act. The ability to choose a better course of action implies a more or less conscious comparison with some ideal standard of conduct. Conscious deliberation extends the range of human self-control beyond the grades achievable by other animals, as Peirce explains in a 1905 passage [10] (5.533):

“To return to self-control, which I can but slightly sketch, at this time, of course there are inhibitions and coördinations that entirely escape consciousness. There are, in the next place, modes of self-control which seem quite instinctive. Next, there is a kind of selfcontrol which results from training. Next, a man can be his own training-master and thus control his self-control. When this point is reached much or all the training may be conducted in imagination. When a man trains himself, thus controlling control, he must have some moral rule in view, however special and irrational it may be. But next he may undertake to improve this rule; that is, to exercise a control over his control of control. To do this he must have in view something higher than an irrational rule. He must have some sort of moral principle. This, in turn, may be controlled by reference to an esthetic ideal of what is fine. There are certainly more grades than I have enumerated. Perhaps their number is indefinite. The brutes are certainly capable of more than one grade of control; but it seems to me that our superiority to them is more due to our greater number of grades of self-control than it is to our versatility."

Logic itself, as a normative science (one which can distinguish between good and bad thinking), is a means of exercising control over control of self-control. 'Logic regarded from one instructive, though partial and narrow, point of view, is the theory of deliberate thinking. To say that any thinking is deliberate is to imply that it is controlled with a view to making it conform to a purpose or ideal' [5] (p. 376). In Peirce's view, recognition of that ideal is ultimately an esthetic judgment, to which most people (not being philosophers or logicians) give little critical attention. They settle instead for conformity to 'a particular ideal' which is 'nothing but a traditional standard' [5] (p. 377), and thus do not rise to the highest grade of self-control. This kind of conformity is often the most reliable guide in practical matters, and certainly stabilizes the community, but does not Inform its collective habits since it cannot change them. Here we get our first glimpse of the creative tension between individual and society, to which we will shortly return.

Deliberate thinking is inhibitory because each step to a higher level of abstraction introduces a delay into the acting-out of the impulse, instinct, habit or thought which is thus made the object of 
attention. But this Hamlet-like penchant for delay which makes conscious self-control possible arises from a natural tendency which can be traced back even to prebiotic levels. This tendency is observable in any physical system which can be seen as using energy to do work: 'in a very general sense, work imposes impediments upon energy gradient dissipation, slowing it down from its fastest possible rate, resulting in delaying its dissipation all the way to heat energy’ [23].

In cybernetic terms, human consciousness can be taken as an enhancement of the negative feedback loops which constitute homeostatic regulation in living systems. Positive feedback loops would seem to contribute more to growth, since they act to increase the focal variables which they monitor. In the behavior of any dynamic system, they 'amplify particular variations, leading to the emergence of novelty’ [24]. Positive feedback may well have played a key role in the origin of life itself [25]. But without negative feedback to stabilize the system, habits cannot be consolidated or system integrity maintained-and this too is essential to growth of system complexity.

If we think of sensation as input (as in classical empiricism), and conduct as output, of the work done by the nervous system, then its evolution appears to consist of adding more feedback loops between input and output. In the human brain, only a small minority of the impulses propagated by neurons consist of sensory input or motor output. Most of this internal looping or 'reentrant' processing [26] is quite beyond conscious control, and would constitute what Peirce calls 'instinct' as opposed to 'reasoning.' But just as the impulse to reason is itself instinctive, the inhibitory feedback loops which introduce delays between impulse and action provide the substratum of our conscious theorizing and abstract thinking.

As we have seen, abstraction affords the opportunity for higher grades of self-control. But if we have abstracted 'a particular ideal' from our deliberations - say, the ideal of 'economic growth'—and conform to that uncritically, we lose the benefit of feedback from experience and experiment that could stimulate real growth, which is an increase of Information. Real growth would lead to a more mature relationship between humans and their socio-ecological context. Rapid growth in size and energy consumption is characteristic of systems in their youth [27, 28]; the current obsession with economic growth fits this pattern, signifying the immature state of global human culture. Peircean growth, on the other hand, advances through every degree of self-control toward the ideal limit of the Whole Truth, without accumulation or consumption of resources. David Korten [29] has written that 'Information is the one resource which is nondepletable and increases its real-wealth value when widely shared.' This is true of Peircean 'information' (if we consider it as a resource rather than a process), but much less true of other quantities bearing that label, as we shall see.

\section{Bateson, Bubbles and Classical Information}

When our hyperactive culture loses the critically conscious degree of self-control which could Inform its practice, negative feedback becomes discontinuous, taking the form of violently disruptive shocks rather than regulative inhibitions. Obvious examples are the recent 'bubbles' in economic systems and the predictable (but often unpredicted) bursting of those bubbles. Uncontrolled consumption also leads to the positive feedback loop of climate change, for instance when high temperatures lead to higher energy consumption for air conditioning, or to increased risk of forest fires. Gregory Bateson saw this pattern emerging, and in a 1968 lecture described it in terms of 
'Conscious Purpose Versus Nature' [30]. In his view, the linear thinking which characterizes the conscious mind when partial to some special purpose or interest tends to interfere with the cybernetic (nonlinear, self-correcting) functions of the system, especially when the effects of this partiality are amplified by technology. Here is Bateson's explanation [30] (p. 434):

“Today the purposes of consciousness are implemented by more and more effective machinery, transportation systems, airplanes, weaponry, medicine, pesticides and so forth. Conscious purpose is now empowered to upset the balances of the body, of society, and of the biological world around us. ... On the one hand, we have the systemic nature of the individual human being, the systemic nature of the culture in which he lives, and the systemic nature of the biological, ecological system around him; and on the other hand, the curious twist in the systemic nature of the individual man whereby consciousness is, almost of necessity, blinded to the systemic nature of the man himself. Purposive consciousness pulls out, from the total mind, sequences which do not have the loop structure which is characteristic of the whole systemic structure. If you follow the 'common-sense' dictates of consciousness you become, effectively, greedy and unwise ... I use 'wisdom' as a word for recognition of and guidance by a knowledge of the total systemic creature."

Bateson's point, of course, was not that we should be less conscious, but that a narrow focus on preconceived purposes should not blind us to the integrity of natural systems. Peirce argued in a somewhat similar vein that a focus on 'practical' or socially useful purposes was incompatible with 'Theory,' or the purely scientific quest for truth. But before looking further into this argument, let us consider how both Bateson's and Peirce's concepts of information differ from that which prevailed in what I call 'classical' information theory, the one which emerged out of the Second World War to dominate 20th-century 'information science.' I call it 'classical' because its peculiar usage of the term 'information' has become so well entrenched, even though the Peircean concept is much better grounded in the longer-term tradition of logic.

This classical concept of information was developed for engineering purposes-in other words, information thus defined is considered only as instrumental to a preconceived 'conscious purpose,' as Bateson would call it. Classical (Shannon-Weaver) information theory 'presumes that signals are meaningful codes established in a system of signs, such as the Morse code for the alphabet, that makes sense for humans' [2] (p. 38). Thus it withdraws attention from the act of meaning and its context by taking them for granted. Bateson regarded this as a misguided attempt to simplify the engineering task. 'By confining their attention to the internal structure of the message material, the engineers believe that they can avoid the complexities and difficulties introduced into communication theory by the concept of "meaning"' [30] (p. 414). His definition of information as 'any difference that makes a difference' [31] (p. 250) does just the opposite: 'making a difference' (to a system, its behavior or its habits) is virtually synonymous with meaning something to that system-or as Peirce would put it, determining that mind or quasi-mind to an interpretant.

The key to Bateson's concept of 'difference' lies in his 'notion of a dividing line between the world of the living (where distinctions are drawn and difference can be a cause) and the world of nonliving billiard balls and galaxies (where forces and impacts are the "causes” of events') [31] (p. 7). He called 
these two universes creatura and pleroma respectively (terms drawn from gnostic sources via Jung). In the pleroma, all causality is reduced to what Aristotle called 'efficient' causes, which appear to work in a linear and mechanical fashion when 'formal,' 'material' and 'final' causes are left out of the picture. (Bateson did not explicitly advocate the fourfold Aristotelian view of causality, but Peirce did, especially in his later work.) The kind of difference-making that occurs in the creatura, on the other hand, is nonlinear, involving loops, cycles or circuits which cannot be reduced to linear 'cause and effect.' Peirce also advocated a more comprehensive view of causality, but for semiotic rather than cybernetic reasons-for instance in this 1904 letter [9] (p. 31-2):

"It appears to me that the essential function of a sign is to render inefficient relations efficient, - not to set them into action, but to establish a habit or general rule whereby they will act on occasion. According to the physical doctrine, nothing ever happens but the continued rectilinear velocities with the accelerations that accompany different relative positions of the particles. All other relations, of which we know so many, are inefficient. Knowledge in some way renders them efficient; and a sign is something by knowing which we know something more. With the exception of knowledge, in the present instant, of the contents of consciousness in that instant (the existence of which knowledge is open to doubt) all our thought and knowledge is by signs. A sign therefore is an object which is in relation to its object on the one hand and to an interpretant on the other, in such a way as to bring the interpretant into a relation to the object, corresponding to its own relation to the object."

As we have seen above ([5] p. 435), Peirce identified Thirdness with 'active power to establish connections' - which connects it with Bateson's [31] focus on 'the pattern which connects.' Peirce's statement that 'the essential function of a sign' is to 'establish a habit'—or to change a habit [10] (5.476 ff.) - is also congruent with Bateson's definition of information. The universe of discourse in which a difference (or in Peircean terms, a 'relation') can make a difference ('be rendered efficient') is quite different from the mechanistic universe of 'the physical doctrine'. Of 'habit' in general, Peirce said that 'the striking contrast of its modality to that of any mechanical law is most significant' [10] (1.390). All of this would seem to support a remark by Hoffmeyer [32]:

"Considering the extent to which Bateson's whole thinking turned upon relations between entities (or agents) rather than on the entities themselves, one may wonder why he did not take up the semiotic thinking from Peirce. His famous conceptualization of information as rooted in 'differences that make a difference' comes so close to a genuine triadic Peircean sign as to be nearly indistinguishable.”

The sociologist Luhmann's definition [8] (p. 40) is a variation on Bateson's:

"Information occurs whenever a selective event (of an external or internal kind) works selectively within the system, namely, can select the system's states. This presupposes a capacity for being oriented to (simultaneous or successive) differences that appear to be bound to a self-referential operational mode of the system.”

This expands on the Bateson definition by specifying that the kind of occurrence which 'makes a difference' can only happen within a system capable (to some degree) of what Peirce called 'self- 
control,' and then only when it is oriented to some 'difference' (or as Peirce would say, Secondness). However, the Bateson definition seems more Peircean in assigning a more active role to this Second and not to the system itself: it is the difference that 'makes a difference.' In genuine (Informative) semiosis the Object must determine the Sign to determine the Interpretant. This is a triadic kind of action, as opposed to the dyadic kind embodied in the 'cause and effect' of Newtonian physics, which can account for neither growth nor self-control.

Classical information theory, like Bateson's pleroma, leaves little room for Thirdness. One of its derivatives is the 'information processing' paradigm in neuroscience, which also tends to ignore (by taking for granted) the self-organization and self-control of living systems. The 'processing' of 'information' in this sense changes only the content (not the form) of the current process, which is investigated through measurements of more or less localized electrochemical activity. Computer-brain analogies are also common in 'cognitive science.' Missing from such models, as foreseen by Peirce, are the twin attributes of growth and self-control: we could make a genuine reasoning machine if it could be endowed with these capacities, but 'we have as little hopes of doing that as we have of endowing a machine made of inorganic materials with life' [5] (p. 387). Information in the Peircean sense does not occur in computers or inorganic machines, and theories of 'information processing' seem to leave little room for it. Some other neuroscientific models are more congenial to cybersemiotic views, such as the 'enactive' approach of Varela, Thompson and Rosch [33], or Walter Freeman's 'activist-pragmatist' model [22]. Freeman applies the mathematics of chaos and complexity to the interactions of neural populations to describe habit formation and modification in terms of attractors; he also offers a critique of mechanistic linear models, espousing a concept of 'circular causality' quite similar to Bateson's. But these investigators do not often use the word 'information,' perhaps because the influence of classical information theory has prevented a more Peircean usage of the term from gaining a foothold in the discourse.

\section{Informing the Human Community}

The classical concept of 'information' generally takes neither context nor scale into account. The Peircean concept, on the other hand, reveals different implications when applied to higher-scale systems. Peirce, as we have seen, felt that a community could be considered as a kind of 'loosely compacted person.' His semiotic account of communication entails a growing together ('fusion') of the commens which is ultimately the communal mind of this larger-scale person. The 'state of Information' of any mind depends on the capacity for self-control as Informed by genuine relations with other systems. This raises the question of how 'loosely compacted' a person can be and still achieve self-control—and on the scale of systemic problems addressed by Bateson, whether humanity can self-organize as a global community. If not, it is difficult to see how humanity as a whole can achieve the degree of self-control needed to inhibit the self-destructive effects of human habits amplified by technology and population growth.

Information in the Peircean sense would further the self-organization process by increasing the predictability of those effects and orienting the membership with respect to the state of their mutual relations and their collective relation with their context (the biosphere). But the accelerating growth of the human footprint on the planet is accompanied by an explosive growth of classical (retrievable) 
information, such that the amount stored increases daily by untold millions of gigabytes-and this seems to contribute more to the problem than it does to the solution. Even if it is relevant to human self-control on any scale, which much of it is not, it can only Inform those who bring their attention and collateral experience to it, and then only if they know where to find it and how to decode it. But attention is a limited resource, for which many special interests are competing in the current media marketplace. Consequently those who would be well Informed (rather than acting as consumers of classical 'information') have to invest some effort in filtering out the irrelevant. But if the filters are not themselves well Informed, they may well exclude the very facts and Forms required for self-organization and self-control.

We seem to be witnessing the growth of an information bubble, analogous to the 'credit bubble' which led to the financial 'meltdown' of 1908 and has only been further inflated by the governmental response of increasing the debt load. The general facts that money is debt, that increasing the money supply (by taking on more debt) is inflationary, and that all bubbles burst sooner or later, are effectively obscured when the economic situation is diagnosed as a temporary 'recession' while endless 'growth' and increased consumption are presented as signs of a healthy economy. Indeed money itself is a prime example of abstraction gone wild; a glance at the stock and bond markets, and especially the currency trade, shows that money has become a substitute for real wealth rather than a measure of it. Measuring flows of money could be Informative when it served mainly as a medium for the exchange of real goods and services, but now the daily stock quotations (which surely count as 'information' in the classical sense) have become disInformation. The intended result (or 'conscious purpose') is to maximize energy and resource consumption, rather than optimize it as a well-Informed society would do.

In the United States, which exemplifies this pattern most clearly, Korten [29] describes the situation in terms of 'phantom wealth' (symbolized by 'Wall Street') vs. 'real wealth' ('Main Street'). Since Wall Street owns most of the media and employs an army of lobbyists and public relations specialists to serve its private purposes of short-term profit, the result is a flood of phantom information, disembodied and disconnected from social, economic and ecological realities. The campaign in denial of climate change [34] is one egregious example of this, but such deliberate disinformation can be successfully propagated only in an environment where information itself is typically both inflated and degenerate by Peircean standards. Even when events of global significance are reported accurately, or the media give us access to genuine artistic or scientific insights into who we are and where we are going, any life- or habit-changing effects it might have are likely to be swept away or neutralized by the flood of 'news' and 'entertainment' which minimizes genuine contact with the human Umwelt and authentic dialogue between humans. The classical concept of information lends itself to this development because 'information' thus conceived is easily commodified.

Genuine Information, on the other hand, propagates itself by actually Informing practice within and between communities. This does happen in communities of researchers in the 'special sciences,' as Peirce called them-but the proliferation of those communities due to increasing specialization also contributes to the information 'explosion,' and tends to render communication across disciplinary boundaries more difficult. This problem may correct itself to some extent, insofar as specialization is a luxury dependent on a supply of cheap energy which is probably past its peak already. When credit bubbles burst, the scientific establishment is likely to curtail its own specialization, following the 
principle which Peirce called ‘economy of research’: ‘it does not pay (in any given state of science) to push the investigation beyond a certain point in fullness or precision’ [10] (1.122).

Besides, just as the growth of the brain involves some 'pruning' as connections within it are optimized, the transition to a more mature and sustainable culture and global infrastructure will likely result in some pruning of cultural connections. For example, long-distance transportation of food and other goods now outsourced (to take advantage of cheap labor or lax regulation) will not be sustainable as energy prices rise, and this pattern is already on the wane as the need to rehabilitate ecological systems is increasingly recognized. The cascading effects of simultaneous environmental crisis, peak oil and financial 'meltdown' are likely to accelerate this pruning process. If informed by Peirce's 'critical common-sensism,' with the help of a conceptual framework such as cybersemiotics, this phase could greatly enhance human intelligence. Humanity may have to lose some 'information' in order to be better Informed.

On the other hand, a self-organizing phase shift in the human way of inhabiting the earth will have to overcome the inertia of deeply entrenched habits which, thanks to their very success over the centuries, have now become major liabilities. One of these habits is centralized control of social systems. Dynamic systems theory is one line of investigation that could help reconceptualize 'control' by showing how living systems (including our own bodies and brains) self-organize: control emerges from communicative interaction among components and not from a central command module in a 'topdown’ fashion. Aside from its applications in such diverse fields as biology [35], neuroscience [36], and developmental psychology [37], dynamic systems theory may help to solve the problems now looming so large on the planetary horizon. These are identified by David Orr as problems of ecological design, which 'is not so much an individual art practiced by individual designers as it is an ongoing negotiation between a community and the ecology of particular places. Good design results in communities in which feedback between action and subsequent correction is rapid, people are held accountable for their actions, functional redundancy is high, and control is decentralized' [38] (p. 28-9).

Paul Hawken [39] has tried to show that the self-organization of humanity is already under way, in the form of a decentralized network of community groups which has developed without recognizing itself as a movement. Although these groups lack charismatic leadership and a shared ideology or creed, and focus on local issues, they constitute a single movement in Hawken's view because they readily share Information and resources with neighboring groups in the network, mutually recognizing each other's intentions as valid and sharing what Peirce would call 'instinctive' principles of social justice and ecological awareness. The inhibitory character of this movement on the global scale is indicated by the fact that so many of the groups constituting it think of themselves as 'resistance' movements, resisting globalized control (usually by transnational corporate entities) of their local communities. This inhibitory character is necessary to self-control, as we have seen. When it comes to social systems, control even by a benevolent dictator or governing class is not systemic self-control-it is rather control of the whole system by a part which may well be misguided by its partiality, as per Bateson's remarks on 'Conscious Purpose vs. Nature.'

Some of the Information shared within the global movement identified by Hawken would also count as classical 'information,' but much of it would not, because it is rich in redundancy, which in the classical theory is regarded as the very opposite of information. A healthy social structure, like a 
natural language, has to be massively redundant in its representations of meaning. Otherwise the loss of a single element in the social fabric would be disastrous. This redundancy is maintained-at a considerable expense of energy (though not necessarily money)—by mentoring, according to Jane Jacobs [40]:

"Redundancy is expensive but indispensable. Perhaps this is merely to point out that life is expensive. Just to keep itself going, life makes demands on energy, supplied from inside and outside a living being, that are voracious compared with the undemanding thriftiness of death and decay. A culture, just to keep itself going, makes voracious demands on the energies of many people for hands-on mentoring."

\section{Creative Tensions and Inhabitation}

Of course the need for structural maintenance through redundancy does not negate the need for innovation as conditions change; these needs are complementary. This is as true in community selforganization as it is in the arts and sciences, and it leads to a creative tension between individual energy and social constraint. In terms of the Peircean logic of science, this translates into a tension between abduction (also called 'hypothesis'), which is the source of all new ideas, and induction, which thanks to its accumulation of observations and experimental results enables hypotheses to be tested against experience. 'Every single item of scientific theory which stands established today has been due to abduction' [5] (p. 217), but its establishment is the work of induction (guided by deduction). This tension within pure science enables it to advance knowledge; at the same time, pure science itself stands in a certain tension with applied science, or 'Practice' as Peirce called it, and this tension enables growth in the state of Information inhabited by the whole human community.

Peirce often presented this tension as an opposition like Bateson's 'conscious purpose vs. nature,' and his point was somewhat similar. He argued that a pure scientist, especially in logical or philosophical work, should not be distracted from the disinterested search for truth by 'topics of vital importance.' Like Bateson, Peirce was arguing against a narrow, partial focus on utilitarian 'practical purposes.' Medical research, for instance, becomes a degenerate form of biological theorizing not only when it aims at producing a marketable commodity, but even when it aims at a definitive cure for some disease. As Peirce put it [10] (1.642):

"It is notoriously true that into whatever you do not put your whole heart and soul, in that you will not have much success. Now, the two masters, theory and practice, you cannot serve. That perfect balance of attention which is requisite for observing the system of things is utterly lost if human desires intervene, and all the more so the higher and holier those desires may be."

Peirce's dedication to 'observing the system of things' is perfectly parallel to Bateson's quest for 'the pattern which connects,' and they shared a similar feeling about narrowly practical concerns. Being a theorist himself, Peirce in his later years expressed an attitude toward applied science that verges on contempt. In his Cambridge lectures of 1898, Peirce was quite vociferous on the point that no concern with practical applications - such as making the world a better place, or oneself a better person-should be allowed to interfere with purely scientific investigation; 'the true scientific 
investigator completely loses sight of the utility of what he is about' [10] (1.619). On the other hand, in 'practical affairs,' instinct and tradition are better guides than deliberate reasoning; 'in matters of vital importance, it is very easy to exaggerate the importance of ratiocination' [10] (1.626). Peirce's 'sentimentalism' disapproves of interference by science and philosophy in practical matters such as religion and morality. However, since he regarded scientific reasoning itself as based on a 'ratiocinative instinct' [5] (p. 472), Peirce avoids an absolute segregation between the two: 'I do not say that philosophical science should not ultimately influence religion and morality; I only say that it should be allowed to do so only with secular slowness and the most conservative caution’ [10] (1.620).

A still more balanced view appears in his 'New Elements' essay of 1904, where he takes up the difference between 'the two great tasks of humanity, Theory and Practice,' the former proceeding from the matter with which it is acquainted toward a full embodiment of its form, the latter from the form of its ideas toward their full embodiment in matter. Both are processes of Informing, although 'logic very properly prefers to take that of Theory as the primary one' [5] (p. 304). We have already seen the complementarity between Theory and Practice in the reciprocal relation between 'reasoning' and 'sentiment' explained by Peirce above [10] (1.673). This reciprocal relation amounts to a creative tension between 'the two great tasks of humanity.' For a logician like Peirce, Theory-if it is inquiry leading toward truth by the best available means-is the highest form of Practice. On the other hand, no theory has any meaning unless it has conceivable practical implications. Pragmatism itself is certainly a theory, else Peirce would not have devoted so much effort to proving it (which he never claimed to have done to his own satisfaction). Yet this very theory makes meaning inseparable from Practice. On the scale of the 'community without definite limits' to which all Theorizing is ultimately addressed, its ultimate logical interpretant is a better way of inhabiting its context, which for the human species is the planet Earth.

This brings us (finally!) back to the point at which we started: the need for two kinds of information-sharing, or rather Information, within the human community as a whole, and the necessary tension between these two. Communication between specialized (differentiated) parts of Humanity-as in the beekeeping example-involves a tension between (1) the natural tendency of sciences to specialize and develop a special terminology for the sake of precision, and (2) the need to communicate and collaborate with other members of the human body using a common terminology which inevitably lacks that kind of precision. The first of these was addressed by Peirce as the 'ethics of terminology,' which aims at 'a vocabulary furnishing a family of cognate words for each scientific conception' (Peirce's italics) so that 'each word should have a single exact meaning' [5] (p. 264). He did not address the second quite so explicitly, but he was under no illusion that absolute precision was possible (or even desirable). 'No cognition and no Sign is absolutely precise, not even a Percept; and indefiniteness is of two kinds, indefiniteness as to what is the Object of the Sign, and indefiniteness as to its Interpretant, or indefiniteness in Breadth and in Depth' [10] (4.543). Genuinely Informative communication depends on taking this necessary vagueness into account; the ethical upshot of this would be roughly what some philosophers call the 'principle of charity.' Properly understanding any statement requires you not to 'decode' it into the same thought-signs intended by the utterer, but to interpret it with the degree of vagueness or generality which would affect your response to the whole situation (including the utterer's intentions and your own) so as to bring your conduct more into line with the ideal of wholeness, or community. This is more likely to occur in a semiosphere where the 
idioms of the various arts and sciences are mutually intelligible, and the aim of cybersemiotics is to make it so.

Any statement which is significant in the terms of Peircean pragmatism will make some difference to your way of inhabiting that whole situation. The way we inhabit any domain of our Umwelt (i.e., habitually interact with it or relate to it) is most explicitly represented by what we can say about it. Terms for the objects comprising it likewise inhabit our conceptual structures, our commind or collective Innenwelt. To inhabit means to be in the process of developing habits Informed by actual experience in dialogue with anticipation and the hope of a greater wholeness-'a closer fit between human intentions and the ecological systems where the results of our intentions are ultimately played out' [38] (p. 14).

The systems we inhabit, and the semiosis Informing them, include both cultural and biological dimensions. The biosphere and semiosphere are mutually inclusive: human knowledge of the natural world is part of the human Lebenswelt, which in turn is part of the natural world. Insofar as it is well Informed, the whole human mind takes the whole planet as its body. Each member of that body has a stake in the integrity of the system, indeed is defined by its role therein; yet the health of the system also depends on the integrity of its individual members, for only as autonomous persons bearing witness authentically to their experience can the members authentically Inform the community. Peircean logic and semiotic imply this truth, even though any given member may be redundant in principle. In a public symbolic system the Truth of any utterance depends intimately on its authenticity, and ultimately on the progress of public inquiry toward its end, its final attractor. Likewise the final attractor-or entelechy, as Peirce (following Aristotle) called it—of Practice would be an unbroken continuity of fully Informed inhabitation, which is necessarily interhabitation.

\section{Conclusion}

'Interhabitation' is a triadic (semiotic) concept, signifying here the structural coupling of human habits with their living context (the biosphere) as guided by mutual interaction and communication between members (instances, manifestations) of the global human bodymind. Any text, message or sign capable of effecting a real change in human habitation by representing objects of human experience to that bodymind is genuine Information in the Peircean sense. As for information in the 'classical' sense, we don't need more of it so much as we need to make more effective use of it. Cognitive, biological and physical sciences, along with communication and information technologies, can contribute to this - to the self-organization and self-control of intelligent life on earth-by recognizing their semiotic context and continuing their development accordingly.

\section{References and Notes}

* Note: References are given here in the format required by this journal. Readers can contact the author for an alternate version of the paper which uses the parenthetical citation format commonly used in Peirce studies.

1. Chandler, P. Looting of a small planet. New Internationalist 2009, 9, 16.

2. Brier, S. Cybersemiotics; University of Toronto Press: Toronto, Canada, 2008. 
3. Peirce, C.S. Writings of Charles S. Peirce: A Chronological Edition; Moore, E.C., Fisch, M.H., Kloesel, C.J., Roberts, D.D., Ziegler, L.A., Eds.; Indiana University Press: Bloomington, IN, USA, 1984; Volume 2, pp. 70-86.

4. De Tienne, A. Peirce's logic of information. Seminario del Grupo de Estudios Peirceanos, Universidad de Navarra, 2006; Available online: www.unav.es/gep/SeminariodeTienne.html (accessed on 15 December, 2009).

5. Peirce, C.S. The Essential Peirce, Peirce Edition Project ed.; Indiana University Press: Bloomington, IN, USA, 1998; Volume 2.

6. Hoffmeyer, J. Biosemiotics; University of Scranton Press: Scranton, PA, USA, 2008.

7. Rosen, R. Life Itself; Columbia University Press: New York, NY, USA, 1991.

8. Luhmann, N.; Bednarz, J. Social Systems; Stanford University Press: Stanford, CA, USA, 1995.

9. Peirce, C.S. Semiotic and Significs: The Correspondence between Charles S. Peirce and Victoria Lady Welby; Hardwick, C., Ed.; Indiana University Press: Bloomington, IN, USA, 1977.

10. Peirce, C.S. The Collected Papers of Charles Sanders Peirce, Intelex CD-ROM ed.; Hartshorne, C., Weiss, P., Eds.; Harvard University Press: Cambridge, MA, USA, 1931-1935; reproducing Volume I-VI; Burks, A.W., Ed.; Harvard University Press: Cambridge, MA, USA, 1958; Volume VII-VIII. (Citations give volume and paragraph number, separated by a period.)

11. Peirce, C.S. The Essential Peirce; Houser, N., Kloesel, C., Eds.; Indiana University Press: Bloomington, IN, USA, 1992; Volume 1.

12. Peirce, C.S. Symbol. In Dictionary of Philosophy and Psychology; Baldwin, J.M., Ed.; Macmillan: New York, NY, USA, 1902; Volume 2.

13. Peirce, C.S. Subject. In Dictionary of Philosophy and Psychology; Baldwin, J.M., Ed.; Macmillan: New York, NY, USA, 1902; Volume 2.

14. Deely, J. Four Ages of Understanding; University of Toronto Press: Toronto, Canada, 2001.

15. Peirce, C.S. Signification (and Application, in Logic). In Dictionary of Philosophy and Psychology; Baldwin, J.M., Ed.; Macmillan: New York, NY, USA, 1902; Volume 2.

16. Peirce, C.S. Extension. In Century Dictionary; Century: New York, NY, USA, 1889-1909.

17. Maturana, H.; Varela, F. The Tree of Knowledge: The Biological Roots of Human Understanding, Revised ed.; Shambhala: Boston, MA, USA, 1998.

18. Gell-Mann, M. The Quark and the Jaguar: Adventures in the Simple and the Complex; W.H. Freeman: New York, NY, USA, 1994.

19. Wittgenstein, L. Philosophical Investigations, 2nd ed.; Macmillan: New York, NY, USA, 1958; p. 88.

20. Rosen, R. Essays on Life Itself; Columbia University Press: New York, NY, USA, 2000; p. 199.

21. Deacon, T.W. The Symbolic Species: The Co-evolution of Language and the Brain; Norton: New York, NY, USA, 1997.

22. Freeman, W.J. Emotion is essential to all intentional behaviors. In Emotion, Development, and Self-Organization; Lewis, M.D., Granic, I., Eds.; Cambridge University Press: Cambridge, UK, 2000; p. 225.

23. Salthe, S.N. The natural philosophy of work. Entropy 2007, 9, 83-99. 
24. Granic, I. The self-organization of parent-child relations: beyond bidirectional models. In Emotion, Development, and Self-Organization; Lewis, M.D., Granic, I., Eds.; Cambridge University Press: Cambridge, UK, 2000; p. 274.

25. Loewenstein, W.R. The Touchstone of Life; Oxford University Press: New York, NY, USA, 1999; p. 81.

26. Edelman, G.M. Wider Than the Sky: The Phenomenal Gift of Consciousness; Yale University Press: New Haven, CT, USA, 2004.

27. Salthe, S.N. Development and Evolution: Complexity and Change in Biology; MIT Press: Cambridge, MA, USA, 1993.

28. Ulanowicz, R.E. Ecology, the Ascendent Perspective; Columbia University Press: New York, NY, USA, 1997.

29. Korten, D.C. Agenda for a New Economy; Berrett-Koehler: San Francisco, CA, USA, 2009; p. 135.

30. Bateson, G. Steps to an Ecology of Mind; Ballantine: New York, NY, USA, 1972.

31. Bateson, G. Mind and Nature: A Necessary Unity; Bantam: New York, NY, USA, 1979.

32. Hoffmeyer, J. A Legacy for Living Systems: Gregory Bateson As Precursor to Biosemiotics; Springer: Berlin, Germany, 2008; p. 42.

33. Varela, F.; Thompson, E.; Rosch, E. The Embodied Mind; MIT Press: Cambridge, MA, USA, 1991.

34. Hoggan, J.; Littlemore, R. Climate Cover-Up: The Crusade to Deny Global Warming; Greystone: Vancouver, Canada, 2009.

35. Oyama, S., Griffiths, P.E., Gray, R.D., Eds. Cycles of Contingency: Developmental Systems and Evolution; MIT Press: Cambridge, MA, USA, 2001.

36. Nuñez, R., Freeman, W.J., Eds. Reclaiming Cognition; Imprint Academic: Thorverton, UK, 1999.

37. Thelen, E.; Smith, L.B. A Dynamic Systems Approach to the Development of Cognition and Action; MIT Press: Cambridge, MA, USA, 1994.

38. Orr, D.W. The Nature of Design; Oxford University Press: Oxford, UK, 2002.

39. Hawken, P. Blessed Unrest; Penguin: New York, NY, USA, 2007.

40. Jacobs, J. Dark Age Ahead; Random House: New York, NY, USA, 2004; p. 159.

(C) 2010 by the authors; licensee Molecular Diversity Preservation International, Basel, Switzerland. This article is an open-access article distributed under the terms and conditions of the Creative Commons Attribution license (http://creativecommons.org/licenses/by/3.0/). 